\title{
The Influence of the Skin Microenvironment Air-Liquid Interface on Melanoma
}

\author{
Shuji Toda ${ }^{1}$, Shigehisa Aoki ${ }^{1}$, Kazuyoshi Uchihashi ${ }^{1}$, Aki Matsunobu ${ }^{1}$, \\ Mai Yakushiji ${ }^{1}$, Akifumi Ootani2 ${ }^{2}$, Eisuke Koike ${ }^{3}$ and Nobuhisa Yonemitsu ${ }^{4}$ \\ ${ }^{1}$ Department of Pathology \& Microbiology, \\ Faculty of Medicine \& Graduate School of Medicine, Saga University, Saga 849-8501, \\ ${ }^{2}$ Department of Internal Medicine \\ Faculty of Medicine \& Graduate School of Medicine, Saga University, Saga 849-8501, \\ ${ }^{3}$ Department of Surgery, Koike Hospital, Saga 840-0861, \\ ${ }^{4}$ Department of Pathology, Sasebo Chuo Hospital, Nagasaki 857-1195
}

Japan

\section{Introduction}

The skin that is exposed to atmospheric air is situated at an air-liquid interface (ALI) through its contact with gas phase. Thus, ALI is an essential microenvironment of the skin. In fact, ALI promotes the growth and differentiation of normal keratinocytes (Sugihara et al., 1991). In cutaneous squamous cell carcinoma cells, ALI also accelerates their invasive growth more greatly than submerged condition without ALI (Inoue et al., 2001). ALI is thus considered to be a critical factor for both normal and neoplastic subjects of the skin.

The critical skin neoplasm melanoma is still at present responsible for about $80 \%$ of all skin cancer-related deaths (Miller et al., 2006). This tumor is considered to originate from epidermal melanocytes or their precursor cells (Bennett, 1993). Thus, the epidermal microenvironments seem crucial for the initiation and progression of melanoma cells. Furthermore, the prognosis of melanoma with ulcer formation is worse than that of melanoma without ulcer formation (Grande et al., 2006). Given that skin ulcer causes cutaneous cell types under the epidermis to situate at ALI by the ulcer-induced exposure of them to atmospheric air, ALI may be related to the growth and invasion of melanoma cells. However, it has been unclear whether the skin microenvironment ALI directly affects the biological behavior of melanoma cells.

On the basis of the background above, we have recently demonstrated that ALI promotes the growth of melanoma cells, but not their apoptosis and invasion, through mitogen-activated protein kinase (MAPK) activation (Chong et al., 2010). In this article, we introduce ALI culture system and describe the effects of ALI on the biological behavior of melanoma cells.

\section{Effects of ALI on melanoma cell behavior}

Air-liquid interface (ALI) is a common microenvironment of the skin. However, the influences of ALI on the biological behavior of melanoma cells have been poorly 
understood. To well understand the interesting issue, we first introduce ALI culture system. Next we show that ALI promotes the growth of melanoma cells, but not their invasion and apoptosis, through the activation of mitogen-activated protein kinase (MAPK), using the ALI culture system of two melanoma cell lines of KHm-1 (King et al., 1978) and HMY-1 (Ojima et al., 1998). Finally, we discuss the mechanisms underlining ALI-induced overgrowth of melanoma cells.

\subsection{Air-liquid interface (ALI) culture system}

By application of a double dish-culture method, ALI culture system is organized, as described previously (Toda et al., 2005). Briefly, $2 \mathrm{ml}$ type I collagen gel solution (Nitta Gelatin, Osaka, Japan) was poured into a $30-\mathrm{mm}$ inner dish with a nitrocellulose bottom (Millicell-CM, Millipore, Bedford, MA) and incubated at $37^{\circ} \mathrm{C}$ for $30 \mathrm{~min}$ to solidify the gel. This inner dish was placed into a $90-\mathrm{mm}$ outer dish, and the complete medium was added to both dishes. Then, $1 \times 10^{6}$ melanoma cells were spread onto the gel and they grew confluent within 2 days. At 3 days in culture, the media of the inner and outer dishes were removed, and $10 \mathrm{ml}$ fresh complete medium was added to only the outer dish to create ALI. The cells were exposed to a humidified air supplemented with $5 \% \mathrm{CO} 2$ at $37^{\circ} \mathrm{C}$. In this way, the cells were situated at ALI. In this system, the cells were kept moist and fed by the culture
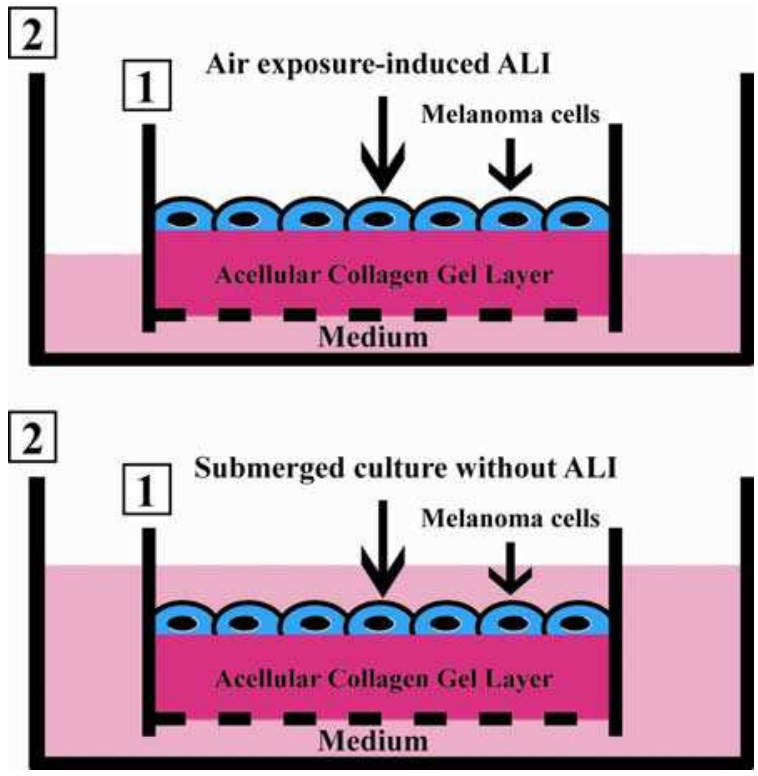

Fig. 1. Collagen gel invasion assay system with (upper panel) or without ALI (lower panel). Upper panel, Melanoma cells are seeded on the acellular gel layer in inner dish (1). The inner dish (1) is put in outer dish (2) with culture medium. In this way, the cells on the gel layer are localized under air exposure-induced ALI. The cells are kept in moist and fed by culture medium that percolates by capillary action from the medium-containing outer dish. Lower panel indicates submerged culture without ALI (control). In these systems, the invasion of melanoma cells into collagen gel is analyzed by the method described in Materials and Methods 

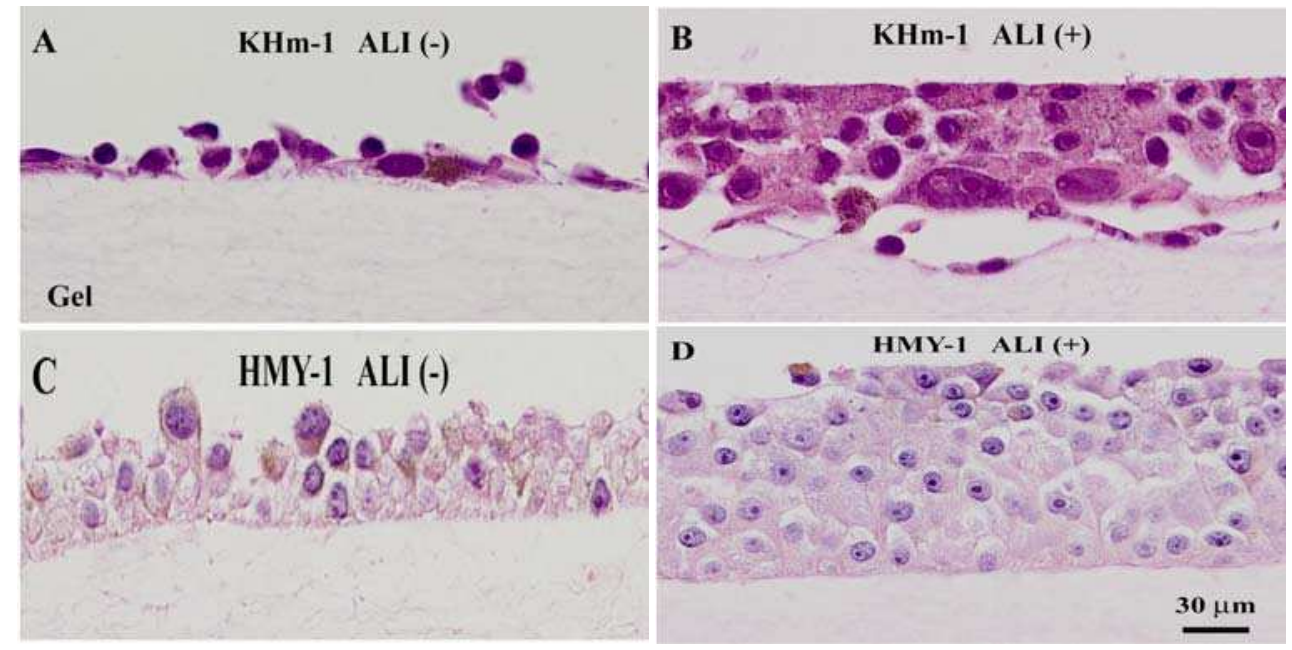

Fig. 2. Histology of two melanoma cell types of KHm-1 (A and B) and HMY-1 (C and D) with (B and D) or without ALI (A and C). ALI promotes the stratification of KHm-1 and HMY-1 melanoma cell types more greatly than submerged condition without ALI. In all conditions, the infiltration of these melanoma cell types into the gel was not observed. Brown pigments indicate melanin pigments
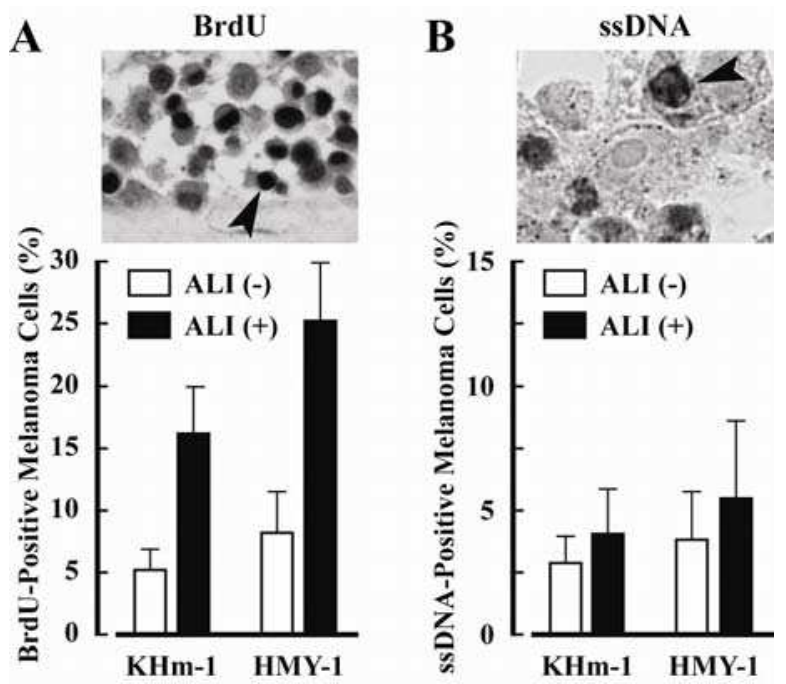

Fig. 3. Growth (A) and apoptosis (B) of melanoma cells with or without ALI, using immunohistochemistry of BrdU (growth marker) and ssDNA (apoptosis marker). BrdU (upper panel in A) and ssDNA (upper panel in B) are clearly detected in the nuclei of KHm-1 melanoma cells in black (arrowhead). The BrdU uptake of melanoma cells with ALI was about 3 times that of the cells without ALI $(p<0.001)$, while melanoma cells with or without ALI showed no significant change in the apoptotic rate $(p>0.05)$ 
medium that percolated by capillary action into cellular layer through acellular collagen gel layer from the medium-containing outer dish. As a control, the cells on the gel were cultured in a submerged condition without ALI. Figure 1 illustrates this culture system. In this system, we can also determine the invasion of various cancer cell types into the gel. In addition, cancer-stromal cell interaction such as the growth and infiltration of cancer cells can be analyzed in the modified system, in which cancer cells are seeded on the stromal cellembbeded or -nonembedded gel (Inoue et al., 2001). Thus, this system has been called "collagen gel invasion assay system".

\subsection{Effects of $A L I$ on growth, apoptosis and invasion of melanoma cells (Chong et al., 2010)}

ALI accelerates the stratification of melanoma cells more prominently than submerged condition without ALI (Fig. 2), suggesting that ALI promotes the proliferation of melanoma cells. In fact, the bromodeoxyuridine (BrdU) uptake of ALI-treated melanoma cells is about 3 times that of ALI-nontreated cells (Fig. 3A). When melanoma cells were cultured in a submerged condition for 2 days following treatment with ALI for 7 days, the BrdU uptake of the cells decreased to that of ALI-nontreated cells. Thus, ALI-promoted growth of melanoma cells is considered to be reversible, supporting our previous study that ALI reversibly promotes fibroblast growth (Toda et al, 2000).

On the other hand, melanoma cells with or without ALI show no significant change in the apoptotic rate that is assayed by immunohistochemistry with single stranded DNA (ssDNA) antibody (Fig. 3B). Interestingly, melanoma cells with or without ALI do not undergo their invasion into collagen gel (Fig. 2). Namely, ALI promotes the growth of melanoma cells, but not their apoptosis and invasion. In addition, dermal fibroblasts accelerate the invasion of melanoma cells cultured on the fibroblast-embedded gel (Fig. 4). The invasion of melanoma cells into the gel is more prominently enhanced by the treatment of ALI than by the nontreatment of ALI. Thus, the combination of dermal fibroblasts with ALI seems critical for the invasion of melanoma cells. Furthermore, adipose tissue stromal cells (ATSCs) as well as dermal fibroblasts promote the invasion of melanoma cells in the same system with or without ALI , supporting our previous study that ATSCs enhance the invasion of gastric adenocarcinoma cells (Nomoto-Kojima et al., 2011). Therefore, subcutaneous ATSCs also seem critical for the spread of melanoma cells.

During the ALI-induced overgrowth of melanoma cells, mitogen-activated protein kinase (MAPK) pathway (Raf-1, MEK-1 and p-ERK-1/2) is activated (Fig. 5).

In addition, the MEK inhibitor PD-98059 that leads to the inactivation of ERK-1/2 (MAPK) inhibits the stratification of melanoma cells even with ALI, although the agent induces a spindle-shaped morphology in the cells (Fig. 6). PD-98059 also abolishes the ALI-promoted the expression of BrdU and pERK-1/2 of melanoma cells (Fig. 6).

Thus, the ALI-affected overgrowth seems to be closely related to the MAPK activation. In our previous study (Toda et al., 2000), ALI-treated fibroblasts proliferate more extensively than the ALI-nontreated cells, while the treated fibroblasts express the MAPK pathway signals more greatly than the nontreated cells. The MAPK pathway may be involved in the mechanisms of ALI-induced cellular overgrowth. As described above, ALI does not induce the infiltration of melanoma cells into collagen gel. In fact, ALI does not promote the expression of the following invasion- and motility-related molecules: MMP-1, MMP-9, laminin 5 and filamin A. Thus, ALI alone may not be involved in the mechanisms of melanoma cell invasion. However, ALI enhances the dermal fibroblast- and ATSC-induced 
invasion of melanoma cells, as described above. This suggests that ALI in combination with these mesenchymal stromal cell types is closely associated with the invasion of melanoma cells. Figure 7 illustrates the effects of ALI and its combination with dermal fibroblasts and ATSCs on the growth and invasion of melanoma cells. Finally, the PI3K-AKT, p16INK4A CDK4/6-RB and $\beta$-catenin pathways, which are suggested to be critical for melanoma cell growth (Smalley, 2009), yet remain to be elucidated. In our laboratory, these molecule regulations by ALI are under investigation.
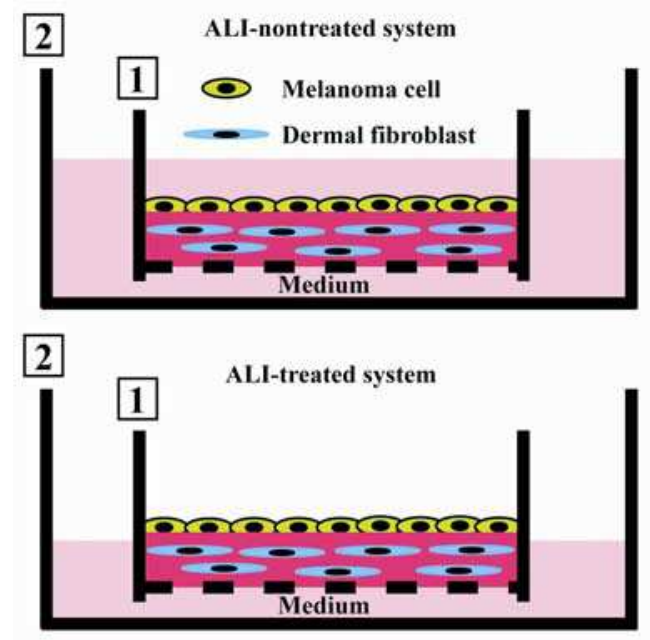

\section{ALI-treated melanoma cells + Fibroblasts}

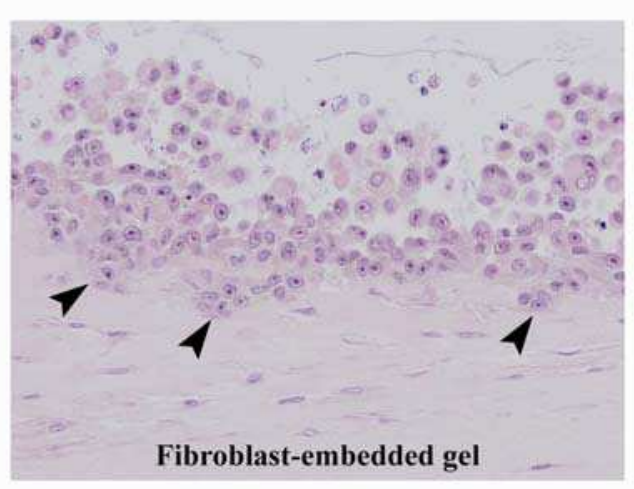

Fig. 4. Culture model with or without ALI for analyzing melanoma cell-dermal fibroblast interaction (left panels), and histology of ALI-treated melanoma cells cultured on dermal fibroblast-embedded collagen gel at 7 days (right panel). Left upper panel, Melanoma cells are seeded on a dermal fibroblast-embedded collagen gel layer in an inner dish with a nitrocellulose membrane as its base. The inner dish is placed in a larger outer dish, and then the complete medium is added to both dishes. Cells are fed by a sufficient medium from both the inner and outer dishes because of the permeability of the nitrocellulose membrane. In this way, melanoma cells are cultured in a submerged condition without ALI under a cancer-stromal interaction. Left lower panel, Melanoma cells are seeded on a dermal fibroblast-embedded collagen gel layer in the inner dish. The inner dish is placed in a larger outer dish, and then the complete medium is added to the outer dish only. In this way, melanoma cells are cultured in an ALT-treated condition under a cancer-stromal interaction. Right panel, ALI-treated melanoma cells undergo stratification on the fibroblast-embedded gel, and then they infiltrate into the gel. Arrowheads indicate the invasion of melanoma cells into the gel

\subsection{Mechanisms of ALI-related behavior of melanoma cells}

ALI is suggested to exert its effects by causing cells to increase their own oxygen availability, which is important for cellular respiration (Bebok, et al., 2001). Therefore, oxygen itself and oxidative stress molecules may be involved in the ALI-promoted overgrowth and MAPK activation. Furthermore, the following possible mechanisms of ALIpromoted growth of melanoma cells may be considered : (1) intracellular diffusion of 

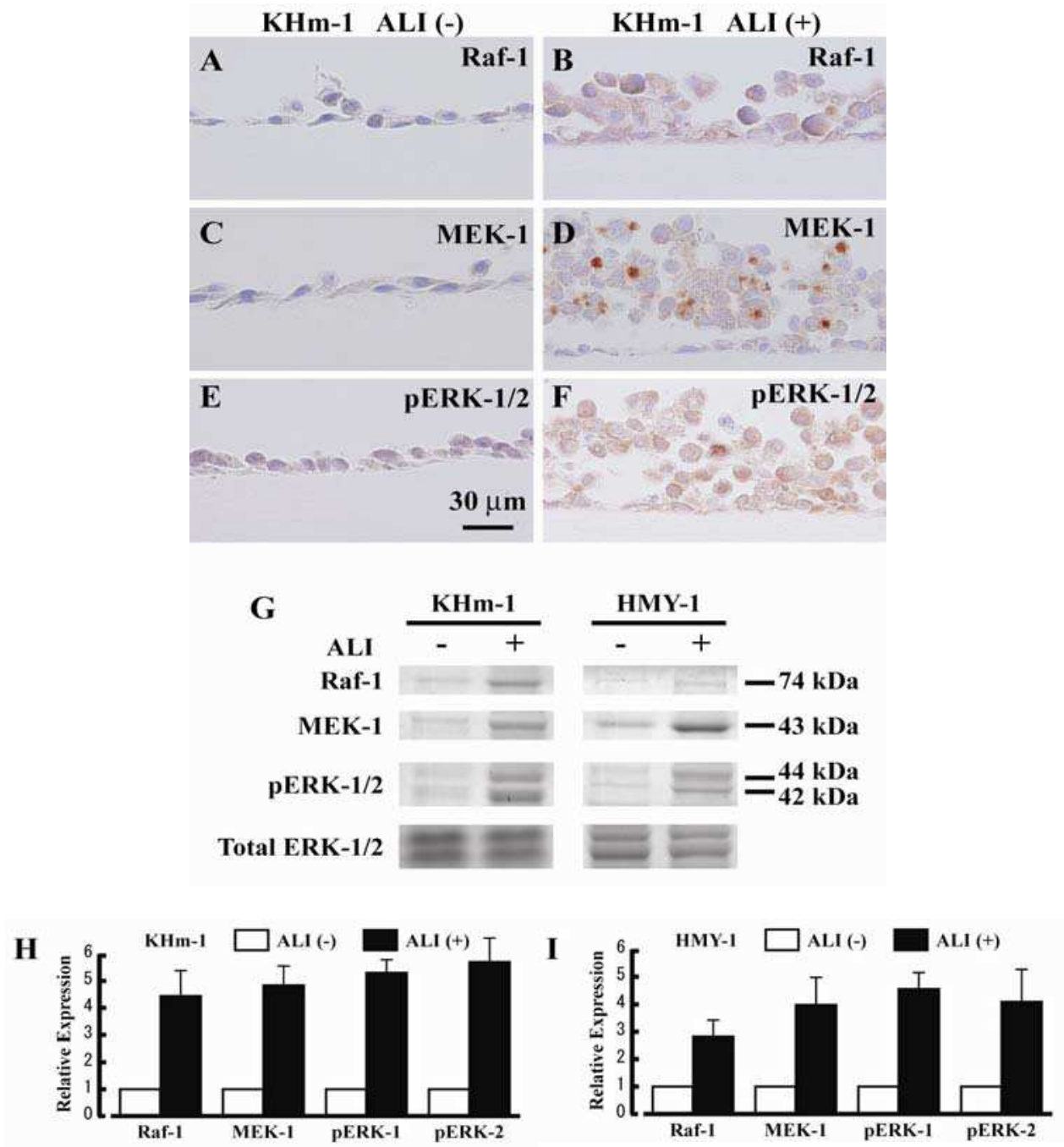

Fig. 5. Expression of MAPK pathway (Raf-1, MEK-1 and ERK-1/2) of melanoma cells with or without ALI. In immunohistochemistry (A-F), KHm-1 melanoma cells with ALI (B, D and F) express Raf-1 (A and B), MEK-1 (C and D) and ERK-1/2 (E and F) more extensively than those without ALI (A, C and D). Western blotting (G) confirmed the immunohistochemical results. Analyses by Densitometry (H and I) show that ALI significantly enhances Raf-1, MEK-1 and ERK-1/2 expression of KHm-1 (H) and HMY-1 (I) melanoma cells (all values, $\mathrm{p}<0.001)$

oxygen through cell membrane may take place more easily in a fluid-less microenvironment of ALI than in a fluid-rich counterpart of submerged condition without ALI; (2) cell growthrelated molecules may be more concentrated within a fluid-less microenvironment of ALI; and (3) ALI may specifically activate cell membrane microdomains (rafts), which regulate a 
variety of signal transduction molecules (Brown, 2002; Kim et al., 2004). To evaluate these possibilities in more detail, further studies are needed. In particular, gas molecules and signaling pathway regarding cell growth, invasion and locomotion should be investigated in the context of ALI-cell membrane interaction.

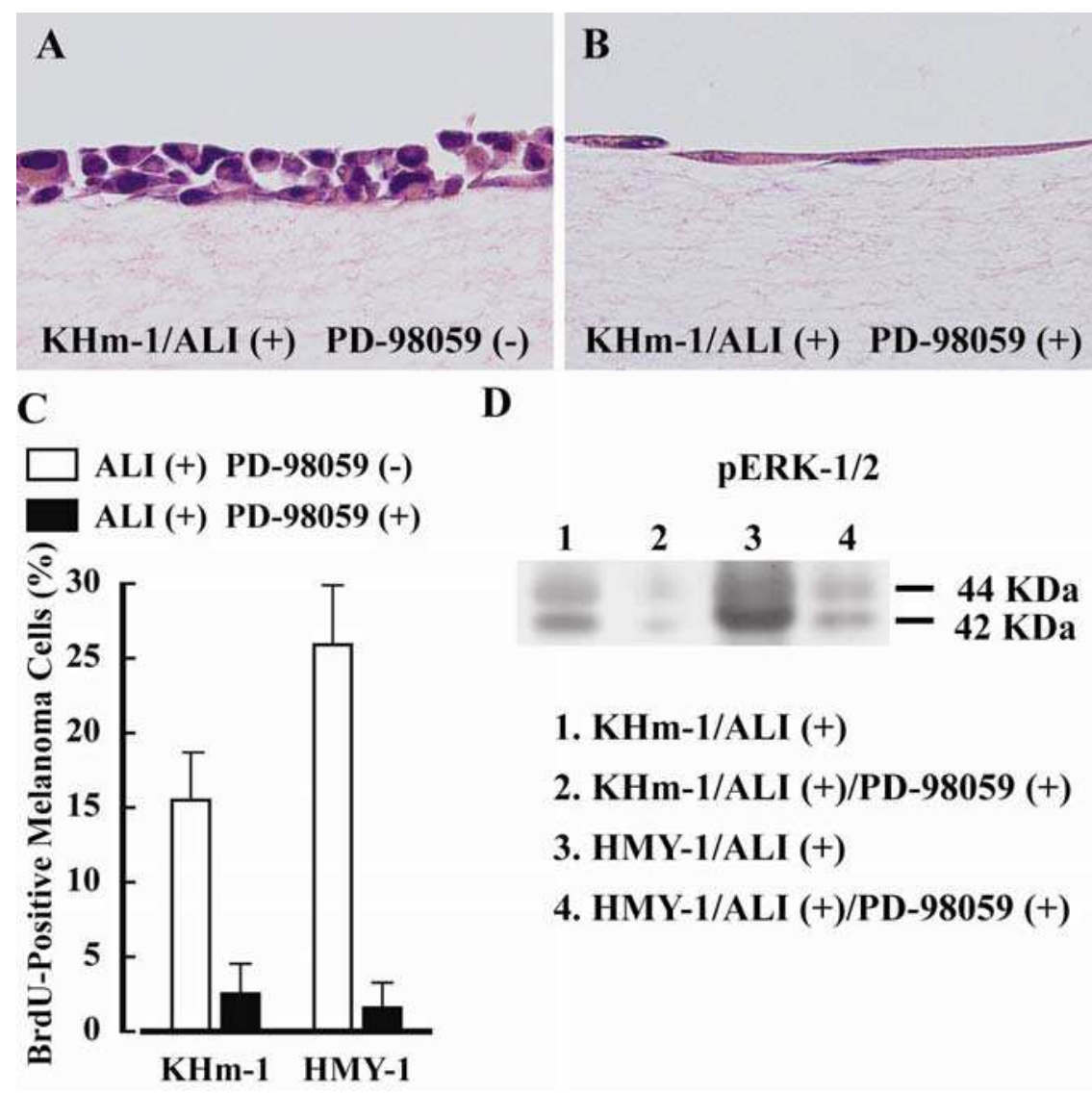

Fig. 6. Effects of the MEK inhibitor PD-98059 on the morphology, BrdU uptake and MAPK (ERK-1/2) expression of melanoma cells with ALI. ALI-treated KHm-1 melanoma cells without PD-98059 (A) undergo cellular stratification on the gel. In contrast, the melanoma cells with PD-98059 show no stratification and they become spindle-shaped (B). In ALI-treated KHm-1 and HMY-1 melanoma cell types, PD-98059 significantly inhibits both BrdU uptake $(\mathrm{C}, \mathrm{p}<0.0001)$ and $\mathrm{pERK}-1 / 2$ expression (D) of the cell types

The prognosis of melanoma with ulcer formation is worse than that of melanoma without ulcer formation (Grande et al., 2006). Skin ulcer seems to cause the cutaneous cell types of the dermis under the epidermis to situate at ALI by the ulcer-induced exposure of them to atmospheric air. In general, normal and cancer cell types are supported by the interstitum that has two major types of solid structures: (1) collagen fiber bundles and (2) proteoglycan filaments (Guyton and Hall, 2000). The interstitial fluid, which is derived by filtration and 
diffusion from capillaries, is entrapped mainly in the minute spaces among proteoglycan filaments. This combination of proteoglycan filaments and the fluid entrapped within them (gel water) organizes a moist tissue gel of the interstitum, while intravascular space has rich fluid (free water) due to both the existence of much serum and the lack of the matrix meshwork. In the moist gel, oxygen and nutrients are also supplied from capillaries. In this way, the ALI microenvironment seems to be created even in the interstitium of the dermis. Thus, the melanoma cell overgrowth that is activated by the ulcer-induced ALI microenvironment of the dermis may be involved in the mechanisms of the worse prognosis of melanoma cells with ulcer formation.

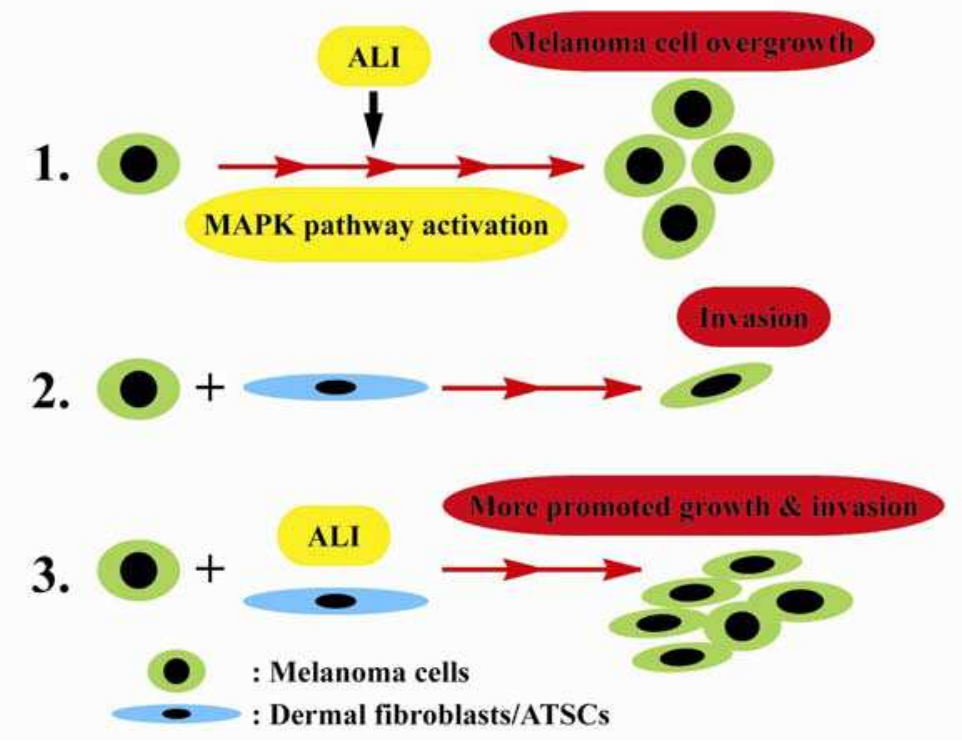

Fig. 7. Scheme of the effects of ALI and its combination with dermal fibroblasts and adipose tissue stromal cells (ATSCs) on the growth and invasion of melanoma cells. 1., ALI induces the overgrowth of melanoma cells, but not their invasion, through the activation of MAPK pathway. 2., Dermal fibroblasts as well as ATSCs induce the invasion of melanoma cells. 3., ALI in combination with dermal fibroblasts as well as ATSCs enhances the growth and invasion of melanoma cells

\section{Conclusion}

Here we have shown that the skin microenvironment ALI promotes the proliferation of melanoma cells, but not their apoptosis and invasion, through MAPK activation. Given that advanced melanoma is not responsive to chemotherapy, immunologic therapy and radiotherapy, ALI may be taken into account for the biology and therapeutic strategy of melanoma. The device that abolishes ALI microenvironment within melanoma tissue may be a promising tool for the treatment of advanced melanoma in combination with the conventional and molecular-targeted therapies. For example, water-rich nano-particles that lead to the abolishment of ALI within the tumor tissue may be created. 


\section{Acknowledgment}

This work was supported in part by Grants-in-Aid from Japanese Ministry of Education, Culture, Sports, Science and Technology for Scientific Research Nos. 18591871, 20592023 and 23591050 (to Prof. Shuji Toda), and personal Grants from Koike Hospital, Sasebo Chuo Hospital and Yamada Clinic (to Prof. Shuji Toda). We thank Messrs. H. Ideguchi, F. Mutoh, S. Nakahara, and Mrs. M. Nishida for their excellent technical assistance.

\section{References}

Bebok, Z., Tousson, A., Schwiebert, L.M. and Venglarik, C.J. (2001) Improved oxygenation promotes CFTR maturation and trafficking in MDCK monolayers. Am. J. Physiol. Cell Physiol. 280; C135-C145.

Bennett, D.C. (1993) Genetics, development, and malignancy of melanocytes. Int. Rev. Cytol. $146 ; 191-260$.

Brown, D. (2002) Structure and function of membrane rafts. Int. J. Med. Microbiol. 291; 433437.

Chong, H.Y., Aoki, S., Uchihashi, K., Matsunobu, A., Yamasaki, F., Misago, N., Piao, M., Tetsuji, U., Yonemitsu, N., Sugihara, H. and Toda, S. (2010) The air-liquid interface, a skin microenvironment, promotes growth of melanoma cells, but not their apoptosis and invasion, through activation of mitogen-activated protein kinase. Acta. Histochem. Cytochem. 43: 1-7.

Grande Sarpa, H., Reinke, K., Shaikh, L., Leong, S.P., Miller, J.R. 3rd., Sagebiel, R.W. and Kashani-Sabet, M. (2006) Prognostic significance of extent of ulceration in primary cutaneous melanoma. Am J Surg Pathol. 30; 1396-400.

Guyton, A.C. and Hall, J.E. (2000) Textbook of medical physiology. 10th, W.B. Saunders, Philadelphia.

Inoue, T., Toda, S., Narisawa, Y. and Sugihara, H. (2001) Subcutaneous adipocytes promote the differentiation of squamous cell carcinoma cell line (DJM-1) in collagen gel matrix culture. J. Invest. Dermatol. 117; 244-250.

Kim, J., Adam, R.M., Solomon, K.R. and Freeman, M.R. (2004) Involvement of cholesterolrich lipid rafts in interleukin-6-induced neuroendocrine differentiation of LNCaP prostate cancer cells. Endocrinology 145; 613-619.

King, L.E. Jr, Solomon, S.S. and Hashimoto, K. (1978) Characterization of a human melanoma cell line (KHm-1) containing phosphodiesterase activity only for cyclic adenosine 3':5'-monophosphate. Cancer Res. 38; 3879-3885.

Miller, A.J. and Mihm, M.C. Jr. (2006) Melanoma. N. Engl. J. Med. 355; 51-65.

Nomoto-Kojima, N., Aoki, S., Uchihashi, K., Matsunobu, A., Koike, E., Ootani, A., Yonemitsu, N., Fujimoto, K., and Toda, S. (2011) Interaction between adipose tissue stromal cells and gastric cancers in vitro. Cell Tissue Res. 344: 287-298.

Ojima, F., Ido, T., Kijima-Suda, I. and Nakagawa, Y. (1998) Biodistribution study of murine monoclonal anti-GD3 antibody in nude mice bearing human melanoma xenografts for development of immunoscintigraphy. Tohoku J. Exp. Med. 185; 89-100.

Smalley, K.S.M. (2010) Understanding melanoma signaling networks as the basis for molecular targeted therapy. J. Invest. Dermatol. 130: 28-37. 
Sugihara, H., Toda, S., Miyabara, S., Kusaba, Y. and Minami, Y. (1991) Reconstruction of the skin in three-dimensional collagen gel matrix culture. In Vitro Cell. Dev. Biol. 27A; 142-146.

Toda, S., Yokoi, F., Yamada, S., Yonemitsu, N., Nishimura, T., Watanabe, K., Sugihara, H. (2000) Air exposure promotes fibroblast growth with increased expression of mitogen-activated protein kinase cascade. Biochem. Biophys. Res. Commun. 270: 961-966.

Toda, S., Yamada, S., Aoki, S., Inokuchi, A. and Sugihara, H. (2005) Air-liquid interface promotes invasive growth of laryngeal squamous cell carcinoma with or without hypoxia. Biochem Biophys Res Commun.326; 866-872. 


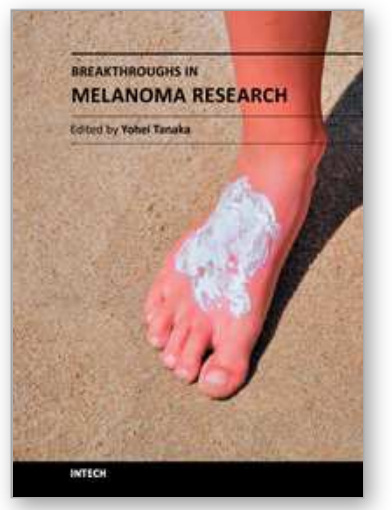

\author{
Breakthroughs in Melanoma Research \\ Edited by Dr Yohei Tanaka
}

ISBN 978-953-307-291-3

Hard cover, 628 pages

Publisher InTech

Published online 30, June, 2011

Published in print edition June, 2011

Melanoma is considered to be one of the most aggressive forms of skin neoplasms. Despite aggressive researches towards finding treatments, no effective therapy exists to inhibit the metastatic spread of malignant melanoma. The 5-year survival rate of metastatic melanoma is still significantly low, and there has been an earnest need to develop more effective therapies with greater anti-melanoma activity. Through the accomplishment of over 100 distinguished and respected researchers from 19 different countries, this book covers a wide range of aspects from various standpoints and issues related to melanoma. These include the biology of melanoma, pigmentations, pathways, receptors and diagnosis, and the latest treatments and therapies to make potential new therapies. Not only will this be beneficial for readers, but it will also contribute to scientists making further breakthroughs in melanoma research.

\title{
How to reference
}

In order to correctly reference this scholarly work, feel free to copy and paste the following:

Shuji Toda, Shigehisa Aoki, Kazuyoshi Uchihashi, Aki Matsunobu, Mai Yakushiji, Akifumi Ootani, Eisuke Koike and Nobuhisa Yonemitsu (2011). The Influence of the Skin Microenvironment Air-Liquid Interface on Melanoma, Breakthroughs in Melanoma Research, Dr Yohei Tanaka (Ed.), ISBN: 978-953-307-291-3, InTech, Available from: http://www.intechopen.com/books/breakthroughs-in-melanoma-research/the-influence-of-theskin-microenvironment-air-liquid-interface-on-melanoma

\section{INTECH}

open science | open minds

\section{InTech Europe}

University Campus STeP Ri

Slavka Krautzeka 83/A

51000 Rijeka, Croatia

Phone: +385 (51) 770447

Fax: +385 (51) 686166

www.intechopen.com

\section{InTech China}

Unit 405, Office Block, Hotel Equatorial Shanghai

No.65, Yan An Road (West), Shanghai, 200040, China

中国上海市延安西路65号上海国际贵都大饭店办公楼 405 单元

Phone: +86-21-62489820

Fax: $+86-21-62489821$ 
(C) 2011 The Author(s). Licensee IntechOpen. This is an open access article distributed under the terms of the Creative Commons Attribution 3.0 License, which permits unrestricted use, distribution, and reproduction in any medium, provided the original work is properly cited. 